\title{
Soil and Groundwater Ecological State Feature and Benefits of Newly Created Teaching Methodology
}

\author{
Nataliia Senenko, Anna Chechel, Valentyna Kirsanova
}

\begin{abstract}
The methodology of the study of the soil and ground water ecological state, consisting of a complex of experimental research and analytical calculations, was developed and presented. The complete cycle of techniques is presented with a demonstration of examples of an analysis of actual soil and groundwater samples, selected in one locality. To determine the content of other components of groundwater, the analytical-calculation method has been applied. The presented cycle of pedagogical methods provides an opportunity to teach students of ecology to master the methods of experimental study of the ecological state of soil and ground water, while receiving the skills of analytical and accounting character and carrying out scientific research work. The methodology allows to quickly and accurately determine the actual environmental state of the main components of the environment. In addition to these advantages, the presented methodology can be applied in any chemical laboratory without the use of expensive equipment. At the same time, the integrated methodology contains the main key recommendations for land management. The developed methodology is useful not only in the educational system of ecologists, land managers, but also for the training of specialists in all branches of the agro-industrial complex with the need to study soil and groundwater, such as agriculture and oil and gas extraction complex.
\end{abstract}

Keywords : Ecology. Methodology of soil and groundwater investigation. Pedagogy. Nature management. Environmental protection.

\section{INTRODUCTION}

The current state of the soils of Ukraine, and in particular, the Poltava region, for its agrochemical, and, so ecological status causeous the significant concerns (Baranovsky 2006). Since all environment components are in a state of dynamic ecological balance, with technogenic impact increasing on the soil an irreversible changes occur throughout the chain. First of all, the chemical composition of the water is changing. Since the rural population of the Poltava region is using water from wells and boreholes (decentralized), and often without chemical analysis of quality, so there is a direct threat to life.

Revised Manuscript Received on November 15, 2019

* Correspondence Author

Nataliia Senenko, PhD in Physics and Mathematics, Associate Professor in Chemistry, Poltava National Technical Yuri Kondratyuk University, Pershotravnevyi Avenue, 24, Poltava, Ukraine, 36011

http://orcid.org/0000-0002-5585-8405

Anna Chechel, Doctor of Economics Sciences, Associate Professor Head of the Department of Public Administration and Management at Donetsk State University of Management

annachechel.ac@gmail.com https://orcid.org/0000-0003-4307-5574

valentyna kirsanova, Associate Professor at the Department of General Science, lecturer in ecology at Danube Institute of National University "Odessa Maritime Academy“ vvkirsanova@ukr.net

https://orcid.org/0000-0002-5857-1426
In (Senenko 2015), the detailed analysis of the main soil degradation causes in the region, sources of soil and groundwater pollutions, the search of possible methods for improving of the main environment components state are presented. Particularly valuable arable land that is involved in intensive use suffers the most (Doroguntsov et al. 2004). The reducing of the organic content of the soil with appropriate dehumification take place, the acidity of the soils and the content of water-soluble salts increase. All this causes salinization and catastrophic degradation of large areas of arable land (Baranovsky 2006). Degumification of Poltava chernozems, significant increase in density and erosion of soil cover are progressing rapidly (Senenko N. 2015 and Sharyi G. et al. 2017).

The most works on the study of the soils ecological state are devoted to the study of the microbiological state. So, Skopp et al. (1990) studied maximal microbial activity depending on water content, its macro-component state, soil moisture and its basic physical parameters. The relationship between the aeration-dependent microbial activity and the water content in the soil, which facilitates the evaluation of the indirect effects of soil management and treatment is established. CAM van Gestel (2012) studied the ecological state of soil for ecotoxicity through so-called biomarkers. The basis for assessing ecotoxicological risks in soils is biotests for toxicity. Ecotoxicogenomic tools will require significant further research before they can be applied in the practice of assessing the ecotoxicological risks of soil. CAM van Gestel (2012) began to develop the concept of a "chemical" ecology of stress. It is concluded that the assessment of ecotoxicological risks in soils will be more reliable and significant from the expansion of experiments on the study of the chemicals toxicity influence on biota. Harris's scientific work (2009) is devoted to the study of soil biodiversity and ecological state. He proves the important role of microorganisms "in the functioning of soil in the cyclization of nutrients, structural formation and interaction of plants, both positive and negative". He notes the emergency role of the restoration of degraded ecosystems. Alves and Cardoso (2016), also explores the soils ecological status according the living organisms state. He considers the soil invertebrates as a classic example of a terrestrial ecosystem service. The author also emphasizes the role of soil fauna in assessing the risk of potentially polluting substances for the terrestrial environment, taking into account the sensitivity of these organisms in comparison with other soil characteristics. Also, the problem of increasing the certainty and the reliability of the laboratory ecotoxicological analyzes results is indicated in the work. Therefore, the basic needs of such research in the global and regional perspectives

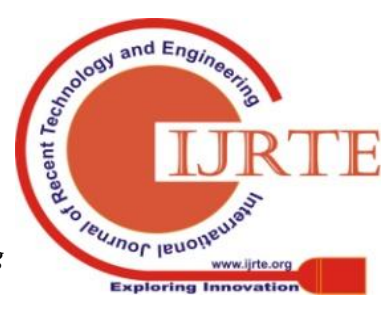


are discussed. The general conclusion derived from the results of research on the ecological state of soil based on biota is the need to pay more attention to exposure, bioavailability and toxicokinetics, as well as to develop a better understanding of the soil organism's ecology for understanding of the consequences of long-term chemical influence. The relationship of the concept of "environmental state of the soil" to the biota state is true, but it is impossible to reject such a reliable instrument as a chemical analysis.

The problem of soils chemical state investigation was studied by many scientists in the world. But research was mainly carried out to solve a narrowly specified problem.

The authors studied the works of soil researchers. The analysis of the historical formation of the chemical analysis of soils was carried out by Anderson (1960). Although the author has provided information on identification of the elements, yet the emphasis is on methods for determining potassium and phosphorus. This information is useful for agrochemical soil studies and for a more specific geochemical investigation. Percival (1942) presented the basic methods of chemical analysis, based on the techniques initiated by Morgan, which makes it possible to determine the eight most important components of the soil.

But the complete soil analysis by chemical methods was presented by Gedroits (1932). It gives possibility to perform the analysis of all soil chemical content. In addition to a detailed description of the methods of soil chemical analysis, the theory of the use of correlation analysis in the study of soils is presented here. The possibility of evaluating soil studies by correlating the values of specific resistance with soil properties is proposed by Hisyam et al. (2017). Soil samples have been laboratory-tested for their respective properties. Then all data were analyzed using correlation analysis. A correlation between the values of specific resistance and moisture content was found. As a result the empirical formula that can be possible to assess soil moisture was obtained. But this is the definition of single indicators that do not give a complete description of the soil ecological state.
Lehmann
and
Stahr
(2007),

Mitchell A. Pavao-Zuckerman (2009) and Byrne (2007) paid attention to the fact that anthropogenic and natural urban soils are of increasing importance in the world as a "fundamental ecological asset for land use planning" and a basis for fundamental soil sciences, since their properties are very different from the landscape soil. In this case, the physical-chemical analysis is also the main "tool"

Alqadad et al. (2017) studied the problems and difficulties encountered during soil research in cities. In order to solve the problems of soil study, the authors present solutions based on the intellectual technology, which includes: a geotechnical information system with updated data on the profile of the soil, soil surface, utilities and water level; tools for data management, analysis and visualization; and a user interface that allows authorities, companies and citizens to access authorized data through a graphical interface, update data and send messages and warnings in case of any incident. Finally, the researchers provide a perspective on the development of intelligent drill units that capture data related to the operation of the drilling machine, and transmit data to the system of intellectual soil investigations. That is, such a smart system should be implemented from each integrated soil study, incorporated into the database and used to identify correlations. It is obvious that the methods of soil study are specific, aimed at solving a particular problem. However, as noted by Hafeth (2018) the study of soil areas is an aggregate of analysis methods for the indicators determination, since all of them affect the cost of all projects. Undoubtedly this also affects to costs of projects on the restoration, protection and conservation of soils.

Important works on the chemical analysis of the soil and the influence of its chemical composition, and, consequently, the macro-component composition of the soil solution on the physiology of plants as the basis of the environment date back to the beginning of the last century. Hoagland (1925) presented the important conclusion, where he emphasized that the physiology of plants depends on the soil chemical content, namely, soil solution. Therefore, it is important to analyze a large number of experiments on the study of soil-plant systems.

To obtain more reliable results in the study of soil ecology, it is necessary to combine the efforts of scientists, but the chemical analysis should be basic.

Therefore, for ecological education it is necessary to apply precisely the methodology of soil chemical analysis, to prove the indisputable necessity of chemical researches of its condition conducting. The most of educational curricula in environmental education generally minimize the role of chemical research. This is probably due to the need for material support for chemical laboratories. That is why in some institutions of higher education the disciplines "Analytical chemistry" or "Methods of chemical analysis" are excluded from the curriculum of ecologists. But without clear knowledge about the significances of the soil physical and chemical indicators it is impossible to determine its environmental state. Therefore, the methodology of soil parameters chemical analysis should provide the necessary level of knowledge, abilities and skills for the analysis of its ecological state.

Thus, firstly, in order to determine the ecological state of the soil, it is necessary regularly to investigate its basic physical and chemical parameters. There is no universal methodology for soil studies, namely, the research is rather long and requires high-skilled researchers in experimental investigations. So, scientists are seeking and refining techniques and approximating them to determine the most important indicators for their field of activity and the necessary results.

Therefore, the purpose of this work was to develop a series of methods of integrated soil analysis and groundwater extraction on the basis of correlation analysis to teach the discipline "Soil Science" to students of environmental specialties for the implementation of reliable control of the basic physical and chemical indicators of soil and ground water, analysis of their condition, providing the necessary recommendations for recovery. The basic concept is developed using the methods and techniques presented in the authors' works Birukov et al (1977), Nazarenko et al. (2004), Korsak and Plahotnik (2004) and Gedroits (1932).

The actuality of the work lies in the possibility of implementing a methodology for determining the state of soil through the study of basic physical and chemical indicators, and this can be done experimentally in a chemical laboratory by physical and chemical analysis methods without additional extremely expensive devices. If necessary, a set of 
techniques allows increasing the list of investigated indicators, does not exclude the possibility of additional research, but each determined indicator in the application of correlation analysis provides reliable information. That is, the selected indicators are related to each other, so the method of correlation analysis can predict the result and verify its reliability. The low cost of the proposed research methods is particularly important for determining the ecological state of the environmental components of countries with insignificant material resources, and, moreover, as stated in Hafeth's work (2018), this is also important in determining the soils state for engineering and technical structures.

The structure of the discipline and teaching methodology

The essence of the proposed integrated soil study is to combine experimental research with analytical and calculation methods including previous a thorough literary search. Actually, in essence, this is a scientific work with the requirements, starting from the methods of sampling the real soil samples, which no one has researched.

The discipline consists of a theoretical (lecture) part and a practical one. The practical part, in turn, consists of laboratory and course work. Students-ecologists independently take samples of soil, examine it, make calculations and conclusions, issue coursework and publicly present. Course work, in turn, is divided into experimental and analytical calculation parts. On the whole, the experimental part of the course is structured in such a way that students use the results obtained in laboratory classes to test the validity of the experiment and the calculated part of the coursework. Therefore, students are interested in carefully conducting research, are aware of the mistakes that have been made in their work, and rework the experiment themselves, because during analytical calculations they can check the accuracy of the results. A feature of classroom planning is that each student should be able to perform the experimental and computational parts of the course work during this time, verify the accuracy of the obtained results, conduct correlation analysis based on experimental results, make appropriate conclusions, issue coursework as a report on the basis of experimental data scientific work with the relevant requirements, pass the teacher to the check. If there are no blunders in the work submitted for testing, the teacher gives an opinion "on defense", and the student presents the coursework to the public. Of course, for sections with an experiment and validation of the obtained results need to allocate time for additional research. If a student has made inaccuracies in the experiment and he claims to be highly rated of his work, then he will do the research once more. In the description of the course work, he necessarily indicates the mistakes made in the previous experiment, analyzes the causes of errors. If the time limit for working in the laboratory has been exhausted, then the student analyzes possible errors, but he can not claim a high score to complete the experimental part of the course work. During the coursework, the teacher controls and evaluates a schedule of rhythmic performance. All the necessary work is divided into stages of 5-10\%, depending on the time required for the experiment. The overall rate of the coursework carried out on a 100 point system. 20 points are assigned for the evaluation of the experimental part, 20 points - for the analytical and calculated part, 10 points - for writing and execution of a work report, 50 points - for the presentation. When a student publicly presents the results of coursework, he must answer 5 mandatory questions, each is rated on a 10-point scale. In case of delays of the coursework executive plan, the percentage of lag is subtracted from the total number of points.

This teaching methodology teaches students to self-assess their work, to realize that laboratory work is not for the teacher, not for the mark, but for themselves, for the development of their personality as an environmental specialist.

Methodology of complex experimental study of soil samplesThe essence of the complex study of the soil ecological state is to determine the basic physical and chemical parameters, the macro-component state of soil aqueous extraction, the content of water-soluble salts and the use of the analytical and calculation method for the quantity detection of sulfate ions and sodium ions. For the presentation of pedagogical methodology training students-ecologist we are using experimentally determined indices of soil samples of the settlement of Poltava region as an example. A water extraction of soil was investigated in order to determine the degree of soil influence on the chemical composition of groundwater, which the population uses for drinking purposes. Soil samples were taken in accordance with DSTU10381-6-2001 "Quality of soil. Sampling". The water of the dug well was taken from the same site from $18 \mathrm{~m}$ depth. The task of this part of the work was to determine the effect of chemical composition of the soil on the quality of water and to establish the component of the groundwater, which is determinant in the formation of this aquatic horizon - soaked water or soil flow. All results are recalculated to $100 \mathrm{~g}$ of soil.

\section{RESULTS}

Our studies have revealed: Hygroscopic soil moisture (thermostatically) - 3.83\%, hygroscopic soil moisture (hydrostatic method) $-3.85 \%$, soil density (pycnometric method) $-2.53 \mathrm{~g} / \mathrm{cm}^{3}$, moisture content of the soil (weight method) - $14.11 \%$, organic matter content (by oxidation-reduction titration and weight method) $-1.1 \%$, humus content $-0.94 \%$, exchange acidity of soil $-1.89 \mathrm{~mL}$, $\mathrm{pH}$ of water extraction -7.84 , soil weight loss on calcination (WLC) $-7.38 \%$, content of the soil mineral part $-92.62 \%$, total water soluble salts content ( TWSS) - $122.590 \mathrm{mg}$ were determined. The macro-component composition of the soil water extraction was also investigated. Its composition is the content of carbonate ions - 0 mmole-eq; $0 \mathrm{mg}$, content of hydrocarbonate ions (acid-base titration method) -0.570 mmole-eq; $34.70 \mathrm{mg}$; chloride-ion content (argentometry) 0.680 mmole-eq; $24.140 \mathrm{mg}$; content of calcium-ions (complexometric method) - 0.630 mmole-eq;12.630 mg; content of magnesium-ions (complexometric method) -0.420 mmole-eq; $5.100 \mathrm{mg}$.

The peculiarity of the presented methodology is the calculation of the content of sodium ions and sulfate ions based on the results of experimental studies of the macro component composition of the soil water extraction. Since the experimental determination of sodium ions requires specific equipment, and the determination of the content of sulfate ions by the weight method is quite long, we have proposed a method for calculating these ions, the use of which enables to quickly monitor the state of both ground water and the macro-component state of 
natural water in general. The calculated content of sulfate-ions is 0.580 mmole-eq; $27.960 \mathrm{mg}$. The content of sodium-ions is 0.780 mmole-eq; $17.980 \mathrm{mg}$ ). The recalculated content of crystallization water is $2.45 \%$.

Experimentally determined value $(26.400 \mathrm{mg})$ of sulfate ions content by weight method differed from the calculated. The presence of discrepancies indicates the possible content of ions that are not characteristic of the soil extraction. This fact is extremely important in the methodology of soil exploration for ecologists. Accordingly, it gave rise to the search for anions that are not characteristic macrocomponents of soil water extraction. Therefore, in the next stage of the complex study authors are offered a qualitative analysis of soil water extraction in order to check for the presence of specific ions.

Our assumption is confirmed. Nitrate-ions were detected (photocalorimetric method). Their content is $2.050 \mathrm{mg} / \mathrm{L}$ of soil filtrate, or $1.025 \mathrm{mg} / 100 \mathrm{~g}$ of soil. This indicates a slight contamination of the soil surface layer with emissions (most likely domestic) with nitrogen-containing compounds. In addition, we detected the content of total iron and determined their content (photocalorimetric method) $(1.940 \mathrm{mg} / \mathrm{L}$ soil filtrate, or $0.970 \mathrm{mg} / 100 \mathrm{~g}$ of soil).

Calculation of the sodium ions and sulfate ions content in the soil water extraction:

TWSS $=122.590 \mathrm{mg} \Gamma$

$\mathrm{Ca}^{2+}=12.630 \mathrm{mg}(0.630$ mmole-eq);

$\mathrm{Mg}^{2+}=5.100 \mathrm{mg}(0.420$ mmole-eq $)$

$\mathrm{Fe}^{3+}=0.970 \mathrm{mg}(0.052$ mmole-eq $)$

$\mathrm{CI}^{-}=24.140 \mathrm{mg}(0.680$ mmole-eq $)$;

$\mathrm{HCO}_{3}^{-}=34.780 \mathrm{mg}(0.570$ mmole-eq $)$;

$\mathrm{NO}_{3}^{-}=1.025 \mathrm{mg}(0.017$ mmole-eq $)$.

We count the amount of cations $\mathrm{Ca}^{2+}, \mathrm{Mg}^{2+}$ and $\mathrm{Fe}^{3+}$ in mmole-eq:

$\Sigma \mathrm{Ca}^{2+}, \mathrm{Mg}^{2+}, \mathrm{Fe}^{3+}=0.630+0.42+0.052=1.102$ (mmole-eq)

Determine the amount of anions $\mathrm{CI}^{-}, \mathrm{HCO}_{3}^{-}$Ta $\mathrm{NO}_{3}^{-}$in mmole-eq:

$\Sigma \mathrm{CI}^{-}, \mathrm{HCO}_{3}^{-}, \mathrm{NO}_{3}^{-}=0.680+0.570+0.017=1.267$

(mmole-eq)

Calculate the difference between anions and cations

$\Delta=1.267-1.102=0.165$ (mmole-eq)

This is the $\mathrm{Na}^{+}$content in mmole-eq required to balance the total amount of cations equivalent to the number of anions

$\left(\mathrm{HCO}_{3}^{-}, \mathrm{CI}^{-}\right.$, $\left.\mathrm{Ta} \mathrm{NO}_{3}^{-}\right)$.

$\mathrm{m}_{\mathrm{e} \mathrm{Na}}{ }^{+}=22,9898 \mathrm{~g} / \mathrm{mole}$

Determine the content of the first part of sodium ions:

$$
\mathrm{m}_{1 \mathrm{Na}}{ }^{+}=22.9898 \cdot 0.1650=3.7933(\mathrm{mg}) \text {. }
$$

$\Sigma=12.630+5.100+0.970+24.140+34.780+1.025+$

$3.790=82,435(\mathrm{mg})$

Find the difference between the value of the TWSS and the sum of all ions

$122.590-82.435=40.155(\mathrm{mg})$

This is the sum of the content of sulfate ions and the second part of sodium ions.
We accept the number of equivalents for $\boldsymbol{x}$, then using the equivalent masses of sodium ions and sulfate ions, we obtain the equation:

$22.9898 x+48.031 x=40.155$

$71.0208 x=40.155$

$x=0.5654$

Determine the number of ions $\mathrm{Na}^{+}$and $\mathrm{SO}_{4}^{2-}$ in $\mathrm{mg}$ :

$\mathrm{m}_{2 \mathrm{Na}}{ }^{+}=22.9898 \cdot 0.5654=12.9984(\mathrm{mg})$

$\mathrm{m}_{\mathrm{e}}$ so ${ }_{4}^{2-}=\frac{m_{y}}{z}=\frac{32.066+15.999 \cdot 4}{2}=48.031$

(g/mole)

$\mathrm{m}_{\mathrm{SO}_{4}^{2-}}^{2-}=48.031 \cdot 0.5654=27.1567((\mathrm{mg})$

Total amount of sodium ions:

$\mathrm{m}_{\mathrm{Na}}{ }^{+}=12.9984(\mathrm{mg})+3.7933(\mathrm{mg})=16.7917(\mathrm{mg}) ;$

In order to determine the probable influence of the soil on the first and second aquifers, we propose to determine the basic physical and chemical properties of water in the same area dug well.

Therefore, we present the results of determining the basic physical and chemical parameters of water quality. Since the population of rural areas uses drinking water from dug wells, we compared the basic indicators with the norms established by the main regulatory document of Ukraine on sanitary rules and norms National Standard of Ukraine DSTU 7525: 2014 «Drinking Water. Requirements and methods of quality control" (2014). The values of standard values of indicators are given in brackets.

The experimental results obtained are as follows: odor 1 point $\left(<2\right.$ point); color $1.67^{\circ}\left(<20^{\circ}\right) ; \mathrm{pH}=7.99$ (6.5-8.5); alkalinity $-8.02 \mathrm{mmole}-\mathrm{eq} / \mathrm{dm}^{3}\left(1.5-6.5 \mathrm{mmole}-\mathrm{eq} / \mathrm{dm}^{3}\right)$; Total hardness - $14.82 \mathrm{mmole}-\mathrm{eq} / \mathrm{dm}^{3}\left(\leq 7 \mathrm{mmole}-\mathrm{eq} / \mathrm{dm}^{3}\right.$ $\left(<10\right.$ mmole-eq $\left.\left./ \mathrm{dm}^{3}\right)\right) ;$ carbonate hardness - 8.02 mmole-eq $/ \mathrm{dm}^{3} ;$ non-carbonate hardness - 6.8 mmole-eq $/ \mathrm{dm}^{3}$;calcium hardness - 6.64 mmole-eq $/ \mathrm{dm}^{3}$; magnesium hardness - $8.18 \mathrm{mmole}-\mathrm{eq} / \mathrm{dm}^{3}$; water soluble salts content (WSSC) $-1057.00 \mathrm{mg} / \mathrm{dm}^{3}\left(<1000 \mathrm{mg} / \mathrm{dm}^{3}\right.$ $\left.\left(1500 \mathrm{mg} / \mathrm{dm}^{3}\right)\right)$; the content of total iron $-0.08 \mathrm{mg} / \mathrm{dm}^{3}(\leq$ $0.3 \mathrm{mg} / \mathrm{dm}^{3}$ ); calcium content $-133.07 \mathrm{mg} / \mathrm{dm}^{3}$; the content of magnesium ions $-99.47 \mathrm{mg} / \mathrm{dm}^{3}$, the content of nitrate ions is $11.35 \mathrm{mg} / \mathrm{dm}^{3}$ for the conversion of nitrate nitrogen, which exceeds the norm for drinking water $\left(10.00 \mathrm{mg} / \mathrm{dm}^{3}\right)$.

\section{DISCUSSION}

We offer the basics of the methodology of giving the soil characteristics on the basis of the analysis of a complex of experimental results of physical and chemical parameters determination. Since the moisture content of the soil moisture and moisture content are insignificant, this correlates with the low content of organic matter. Such values indicate a low adsorption capacity of soil particles and a predominant content of hydrophobic groups in the structure of humic acids of the humus. A small amount of organic matter completely correlates with quite significant values of density (the soil is compacted) and a small value of exchange acidity. The value of the density is fully consistent with the average rate of filtration of the water extract of the investigated soil. The content of crystallization water is an average, which correlates with weak soil water loss. 
The mass loss of soil during calcination has an average value, which is absolutely consistent with the content of hygroscopic water and the content of organic matter. After calcination, the studied soil has acquired a light-brown color, on the basis of which we can assume that the content of iron oxide (III) is insignificant. The $\mathrm{pH}$ of the soil water extraction indicates the weakly alkaline nature of the soil, which correlates with the chemical composition of the water extraction of the soil. The content of water-soluble salts in the soil is average. This means that the soil under study is not salty. It can be assumed that the soil should not significantly affect the chemical composition of the water of this horizon. The soil does not contain water soluble contaminants, and the content of nitrate ions is insignificant. Probably their presence is caused by the use of mineral fertilizers (saltpeter). It is quite compact. To increase its organic content and to improve fertility, regular organic fertilizers should be recommended.

The quality of groundwater is changing under the influence of regional, local and linear sources of pollution. First, among regional sources mention should be made of the chemicalization of agricultural land and some types of water management activities, including disordered landfills of industrial and domestic wastes, mineral fertilizer compositions and pesticides. As stated in Yatsik (2000), 147 stable centers of groundwater contamination were discovered on the territory of Ukraine and 93 large (over $5000 \mathrm{~m}^{3} /$ day) water intakes of groundwater, the quality of which deteriorated due to anthropogenic impact, were exploited. As for groundwater, it should be noted that in Ukraine as a whole, the area of protected main aquifers is $39.6 \%$, vulnerable $36.2 \%$, conditionally protected $-24.2 \%$. The largest areas of protected groundwater in Ukraine are observed in Poltava (95.3\%), Odesa (81.1\%) and Chernihiv $(77.4 \%)$ regions.

Yatsik (2000) provided a scheme for the use of groundwater in the territory of Ukraine, from which it is obvious that in the Poltava region groundwater is most used

The contents of nitrate ions in the water extract of the soil and in the water of the dug well differ greatly. It is obvious that the impregnated water does not affect the content of nitrate ions in the studied water of the dug well. This indicates another source of their entry into this aquifer, which is an extremely important conclusion in the training of environmental students.

In the investigated water the content of iron ions is small, and in the soil extraction - significant. Impregnated water does not strongly affect the iron content in this aquifer, or the iron-containing compounds are well-kept by the soil.

National Standard of Ukraine DSTU 7525: 2014 «Drinking Water. Requirements and methods of quality control ". The total hardness of water exceeds the standards set by the National Standard of Ukraine DSTU 7525: 2014 «Drinking Water. Requirements and methods of quality control". Therefore it is recommended to boil for carbonate hardness removing and reduce the total mineralization.

The value of alkalinity is greater than normal, but it will decrease with boiling. Since the carbonate hardness is equal to alkalinity, then, after boiling, the non-carbonate hardness will be: $14.82-8.02=6.8 \mathrm{mmole}-\mathrm{eq} / \mathrm{dm}^{3}$, which is satisfactory. That is, it can be a recommendation to improve the quality of water in this case.

Macrocomponent composition of aqueous extraction is characterized by insignificant content of calcium and magnesium ions, which does not correspond to the value of calcium and magnesium content in the investigated water. This proves that these ions enter the water from the aquifer. So, there is another source that can be located at rather significant distances from this water intake.

The $\mathrm{pH}$ of the water under investigation corresponds to the sanitary norms and differs slightly from the $\mathrm{pH}$ of the water extract. This indicates a very small difference in the contributions of cations of strong bases and acid residues of strong and weak acids.

Thus, based on the data obtained, due to the proposed methodology, it can be concluded that the formation of this aquifer is determined by the water of the ground stream.

\section{CONCLUSIONS}

In summary, the authors developed and presented the methodology of the study of the ecological state of the soil and groundwater provides an opportunity to determine the basic physical and chemical parameters, on the basis of which it is possible to determine the presence of mutual influence. This is especially important in identifying possible sources of pollution of the area or the entire aquatic horizon. The example of the analytical and calculation part demonstrates the possibility of calculation for the evaluation of the content of macrocomponents that can not be determined experimentally at the moment. Thus, on the basis of the experimental data obtained, we can conclude that the formation of this aquifer is determined by the ground stream water. To preserve the soil, the positive experience of the scientific and production enterprises, where organic land use is introduced, i.e. chemical compounds and mineral fertilizers are not used, should find state support and institutional consolidation. For example, there is the scientific and production private enterprise "Agroecology" at Poltava region. It is necessary to introduce the assignment of ecological rent to producers of organic products, to form an effective system of state regulation and protection of soil in Ukraine, to consolidate the existing management experience with organic farming technologies.

\section{RECOMMENDATIONS}

In the future, environmental researchers can apply the proposed methodology for soil research, soil extraction and water. As an example of our research, we have shown the degree of instability of the nature-human system. Even minor external influences make significant changes in the chemical composition of the environment, which in turn leads to changes in the human ecology, since a person cannot live in isolation from nature. The human body is an element of nature and develops in accordance with its laws. The laws of nature cannot be canceled. And changes in the chemical composition of the soil and water can be irreversible, as irreversible may be the change in the environmental balance of the environment. Therefore, it is important to study the chemistry of the environment with a further analysis of the impact of changing the main indicators of the state of the ecosystem on the life of mankind in general soon. 
Soil and groundwater ecological state. Feature and benefits of newly created teaching methodology

\section{REFERENCES}

1. Alqadad A., Shahrour I., Sukik A. 2017. Smart system for safe and optimal soil investigation in urban areas, Underground Space Volume 2, Issue 4. 220-226 https://doi.org/10.1016/j.undsp.2017.10.003

2. Alves PRL., Cardoso EJBN. 2016. Overview of the Standard Methods for Soil Ecotoxicology Testing. DOI: 10.5772/62228. https://www.intechopen.com/books/invertebrates-experimental-model s-in-toxicity-screening

3. Anderson M.S. 1960. History and Development of Soil Testing. J. Agric. Food Chem. (82) 84-87. https://doi.org/10.1021/jf60108a001

4. Baranovsky V.A. 2006. Ecological-geographical atlas of Ukraine / Atlas-monograph. M: Varta, p. 61 (220 p).

5. Birukov N.S., Kazarnovsky V.D., Motilyov Yu.L. 1975. Methodical manual on determination of physicochemical properties of soils. Moscow: Nedra,. 177 pp

6. Byrne L.B. 2007. Habitat structure: a fundamental concept and framework for urban soil ecology. Urban Ecosyst 10:255-274 doi: 10.1007/s11252-007-0027-6

7. CAM van Gestel. 2012. Soil ecotoxicology: stateof the art and future directions. Zookeys.;(176):275-96. doi: 10.3897/zookeys.176.2275.

8. Doroguntsov S.I., Muhovikov A.M., Hvesik M.A. 2004. Natural resources: environmental and economic assessment. Kiyv: Kondor.

9. Gedroits K.K. 1932. Soil Chemical Analysis, Moscow-Leningrad: Gos. Publishing House of Agricultural and Collective-Farm Cooperative Literature. $536 \mathrm{p}$

10. Hafeth I. Naji, 2018. Analyzing the Factors Affecting the Soil Investigation Cost. Journal of Engineering and Applied Sciences, 13: 198-203. DOI: $10.3923 /$ jeasci.2018.198.203 URL: http://medwelljournals.com/abstract/?doi=jeasci.2018.198.203

11. Harris J. 2009. Soil microbial communities and restoration ecology: facilitators or followers? Science. $325,573$. doi:10.1126/science. 1094875 pmid: 15192218

12. Hisyam J., Syed B., Syed O. 2017. The Correlation between Resistivity and Soil Properties as an Alternative to Soil Investigation / Indian Journal of Science ang Technology 10(6) DOI: 10.17485/ijst/2017/v10i6/111205

13. Hoagland D.R. 1925. Physiological aspects of soil solution $\begin{array}{lll}\text { investigations. } & \text { Hilgardia } & \text { 227-257. }\end{array}$ DOI:10.3733/hilg.v01n11p227 http://hilgardia.ucanr.edu/Abstract/?a=hilg.v01n11p227

14. Korsak K.V. Plahotnik O.V. 2004. Fundamentals of modern ecology: Study Guide. 4-e ed. Ukraine. Kyiv: IAPM.340 p.

15. Lehmann A. Stahr K. 2007. Nature and significance of anthropogenic urban soils. Journal of Soils and Sediments. 7(4): 247-260. https://doi.org/10.1065/jss2007.06.235

16. Mitchell A. Pavao-Zuckerman. 2009. Scratching the surface and digging deeper: exploring ecological theories in urban soils. Urban Ecosystems, 12(1), 9-20 https://doi.org/10.1007/s11252-008-0078-3

17. National Standard of Ukraine DSTU 7525: 2014. «Drinking Water. Requirements and methods of quality control ". Kiyv. Ministry of Economic Development of Ukraine. 26 p.

18. Nazarenko I.I., Polchina S.M., Nikorich V.A. 2004. Soil Science. Tutorial. Chernivtsi: Books - XXI, $400 \mathrm{p}$

19. Percival G.P. 1942. Modern methods of soil testing. J. Chem. Educ., 19(12) p. 604 Publication Date:December 1, 1942 https://doi.org/10.1021/ed019p604

20. Senenko N. 2015. Analysis of the state of soil, groundwater and possible improvement of their quality. In the book «Energy saving and rational nature use». Oradea University Press, pp. 116-148. ISBN 978-606-10-1452-1.

21. Sharyi G.I, Ivanytska I.O, Senenko N.B. 2017. Analysis of soil fertility in the Poltava region. In the book "Energy, energy saving and rational nature use", Poland Kazimierz Pulaski University of Technology and Humanities in Radom. № 1-2 (7, 8). p. 79 - 85. (ISSN 2409-658X)

22. Skopp J., Jawson J.W., Doran M.D. 1990. Steady-state aerobic microbial activity as a function of soil water content, Soil Science Society of America Journal,.54 No.6:.1619-1625 ref.28. DOI:10.2136/sssaj

23. Yatsik A.V. 2000. Water management in Ukraine., Ukraine. Kyiv: Geneza. 456 p.

\section{AUTHORS PROFILE}

Nataliia Senenko, PhD in Physics and Mathematics, Associate Professor in Chemistry, Poltava National Technical Yuri Kondratyuk University, Pershotravnevyi Avenue, 24, Poltava, Ukraine, 36011 http://orcid.org/0000-0002-5585-8405
Anna Chechel Doctor of Economics Sciences, Associate Professor Head of the Department of Public Administration and Management at Donetsk State University of Management annachechel.ac@gmail.com https://orcid.org/0000-0003-4307-5574

ResearcherID: B-2212-2019

Valentyna Kirsanova, Associate Professor at the Department of General Science, lecturer in ecology at Danube Institute of National University "Odessa Maritime Academy"

vvkirsanova@ukr.net

https://orcid.org/0000-0002-5857-1426 